LESSON OF THE MONTH

\title{
X-linked adrenoleukodystrophy presenting as autosomal dominant pure hereditary spastic paraparesis
}

\author{
C J Shaw-Smith, S J G Lewis, E Reid
}

J Neurol Neurosurg Psychiatry 2004;75:686-688. doi: 10.1136/jnnp.2003.022970

We present a family in which an initial clinical diagnosis of autosomal dominant pure hereditary spastic paraparesis (HSP) was made on the basis of a three generation pedigree in which both males and females presented with a spastic paraparesis. Subsequent biochemical and genetic analysis revealed that the family was in fact affected by the adrenomyeloneuropathy subtype of X-linked adrenoleukodystrophy. In the family described, both males and females were affected by a spastic paraparesis, and there was no male to male transmission, consistent with both autosomal dominant and X-linked inheritance. This report illustrates the importance of assaying very long chain fatty acids (VLCFAs) in any HSP family where there is no male to male transmission.

\section{INTRODUCTION}

The hereditary spastic paraplegias (HSPs) are a group of neurodegenerative conditions that share the principal clinical feature of progressive lower limb spastic paralysis caused by either failure of development or progressive degeneration of the corticospinal tracts. They are subdivided into pure and complicated forms, depending on the presence of additional neurological or non-neurological features. ${ }^{12}$

Pure HSP is the largest HSP subgroup and most of these families show autosomal dominant inheritance, with autosomal recessive inheritance accounting for nearly all of the remainder. There are eight known loci for autosomal dominant pure HSP, and four of the causative genes have been identified. Mutations in two of these genes, spastin and atlastin, account for around $50 \%$ of autosomal dominant pure HSP families. ${ }^{12}$ However, in families lacking a mutation in one of these genes, diagnosis relies on clinical criteria, ${ }^{2}$ which emphasise the fact that pure HSP is a diagnosis of exclusion, and that other potential diagnoses should be sought before arriving at this diagnosis. We present a family in which an initial clinical diagnosis of autosomal dominant HSP was made on the basis of a three generation pedigree in which both males and females presented with a spastic paraparesis. However, subsequent biochemical and genetic analysis confirmed that the family was in fact affected by X-linked adrenoleukodystrophy (ALD). This case therefore illustrates the critical importance of testing for X-linked ALD in every family with apparent pure HSP in which there is no male to male transmission.

\section{CLINICAL HISTORY}

The family relationships are shown in the pedigree (fig 1).

\section{Case 1 (IV I)}

A 26 year old man presented to the neurology service with an 18 month history of progressive difficulty in walking, and a more recent history of inability to run. There were no sensory and urinary symptoms. Neurological examination of the cranial nerves and upper limbs was normal, whereas in the lower limbs, tone was markedly increased, although full power was retained. Lower limb reflexes were very brisk with sustained clonus and upgoing plantar responses bilaterally. Sensation was normal in all modalities.

Initial investigations including full blood count, erythrocyte sedimentation rate, electrolytes, glucose, liver function tests, thyroid stimulating hormone (TSH) immunoglobulins, autoantibody screen, chest $x$ ray and electrocardiogram were all reported as normal. Specific neuroimaging with magnetic resonance imaging (MRI) of the brain and cervical and thoracic spinal cord revealed no pathology. Cerebrospinal fluid protein was mildly elevated at $0.54 \mathrm{~g} / \mathrm{dl}$; no oligoclonal bands were present.

Case 2 (III 1)

A 54 year old woman presented to the neurology service with her son (patient IVl). She gave a history of clumsiness and recurrent falls. There were no bladder or sensory symptoms. Physical examination revealed a spastic paraparesis with some mild asymmetry, being more marked on the left side. Examination of cranial nerves and upper limbs was normal.

\section{Case 3 (II2)}

This was an 82 year old woman, the mother of IIIl and grandmother of IVl. She reported longstanding difficulties with walking but had not formally sought medical advice.

\section{Case 4 (II3)}

This man, the brother of case II2, died in 1979 of renal failure. He had always had some gait difficulty, walking on tiptoe with high foot arches. He is presumed to have been affected by the same neurological condition, although definitive evidence for this is lacking.

In light of the clinical features and apparent transmission pattern in the family, a presumptive diagnosis of autosomal dominant pure HSP was made and the proband was referred to the clinical genetics service for counselling on this basis. However, in parallel with this a venous blood sample was sent for analysis of very long chain fatty acids (VLCFAs) to investigate the possibility of an alternative neurological diagnosis.

The results of the VLCFA analysis strongly suggested a diagnosis of ALD (normal ranges in parentheses): decosanoate (C22): $41 \mu \mathrm{mol} / \mathrm{l}$ (30-112); tetracosanoate (C24): $58 \mu \mathrm{mol} / \mathrm{l}$ (14-80); hexacosanoate (C26): $2.5 \mu \mathrm{mol} / \mathrm{l}(0.33-$ 1.5); ratio $\mathrm{C} 24 / \mathrm{C} 22$ 1.41 (0.44-0.97); ratio C26/C22 0.061 (0.005-0.030). In view of this new information, genomic DNA from the proband was screened for mutations in the

Abbreviations: ALD, adrenoleukodystrophy; $A M N$,

adrenomyeloneuropathy; HSP, hereditary spastic paraplegia; MRI, magnetic resonance imaging; VLCFAs, very long chain fatty acids 


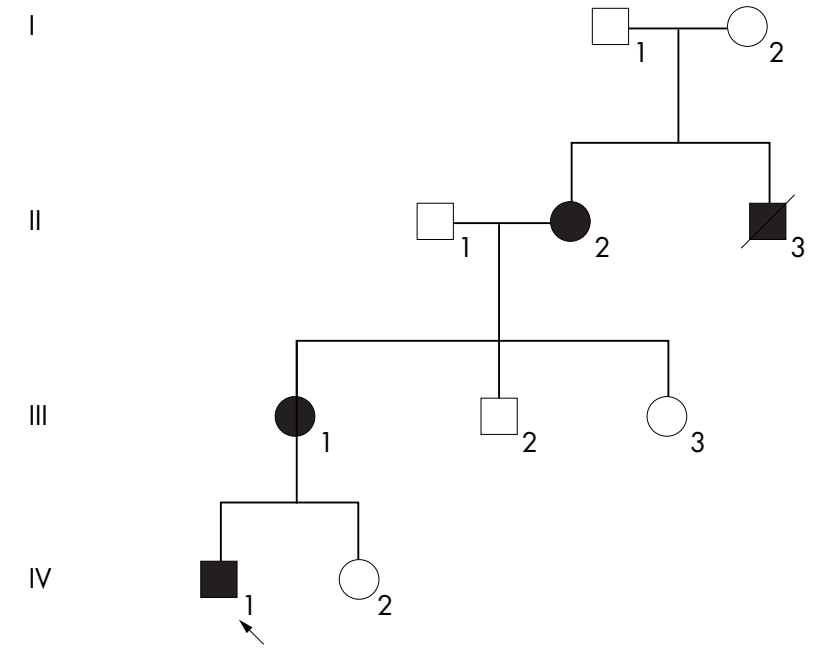

Figure 1 Family tree. Please see text for the description of each case. The consultand is indicated by an arrow. Filled symbols indicate both molecularly confirmed and probable X-linked adrenoleukodystrophy.

ALD gene. A missense mutation 2262G $>$ A, previously reported to be pathogenic based on functional studies, ${ }^{3}$ was identified in exon 9 of the $A L D$ gene, confirming X-linked ALD as the correct diagnosis in this family. Further testing revealed that both the patient's mother and maternal grandmother carried the same mutation. The proband (IV1), his mother, and his maternal grandmother were referred for assessment of adrenal function. Normal results were obtained for each individual.

\section{DISCUSSION}

We present a family in which X-linked ALD presented with features that led to an initial diagnosis of autosomal dominant HSP. X-linked ALD (OMIM 300371) is a disorder of the nervous system white matter and adrenal cortex, with an estimated incidence of approximately $\mathrm{l}$ in $50000 .{ }^{4}$ There are four main clinical subgroups in affected males. The childhood cerebral form manifests usually between the ages of four and eight years with progressive impairment of cognition, hearing, vision, and motor function. It is the most severe phenotype. Adolescent ALD is similar to the childhood form, but onset is typically between the ages of 10 and 21 years. The third phenotype, adrenomyeloneuropathy (AMN), manifests most commonly in the late twenties as progressive paraparesis, sphincter disturbance, and distal sensory loss. It is slowly progressive over decades. The fourth phenotype presents with primary adrenal insufficiency at any age after two years, with no evidence of neurologic abnormality. These clinical subgroups do not breed true within families, and different phenotypes are often found within a single family.

Although ALD is inherited in an X-linked pattern, carrier females do exhibit symptoms and signs of the condition, typically of the AMN phenotype and sometimes these features can be accompanied by adrenal failure. ${ }^{5}$ In one series, ${ }^{6} 61 \%$ of carrier females had some neurological abnormality resembling AMN, with severe disability in $14 \%$. The mean age at onset of symptoms was 37.8 years, later than the typically third decade onset found in males with the AMN phenotype. Therefore, as far as the AMN phenotype is concerned, ALD can be considered to be an Xlinked dominant condition with reduced penetrance and a milder phenotype in females. This does mean that it is possible for X-linked pedigrees to resemble closely autosomal dominant pedigrees, as in this case. Other instances have been previously reported. ${ }^{7}$
The possibility for confusion is compounded by the fact that a distinction between AMN and uncomplicated HSP can not be made on clinical grounds. In both, a spastic paraparesis occurs and may be associated with urinary symptoms and mild sensory symptoms and signs in the lower limbs. In HSP, MRI of the brain and spinal cord are usually normal, though atrophy of the thoracic spinal cord has been observed in some subjects. ${ }^{8}$ Similarly, MRI abnormalities of the brain are often absent in AMN. Brain MRI was normal in $56 \%$ of men and $80 \%$ of women in a series of 119 men and 45 women with the AMN phenotype. ${ }^{9}$ Brain parenchymal abnormalities resembling those seen in childhood-onset ALD are reported in the remainder.

The plasma concentration of VLCFAs is elevated in more than $99 \%$ of males with X-ALD, regardless of symptoms; this assay has a sensitivity of approximately $85 \%$ in female carriers. ${ }^{10}$ Mutation analysis of the $A B C D 1$ gene, mutated in ALD, has a sensitivity of well over $90 \% .^{11}$

Neurophysiological studies should also be interpreted with caution. Apparently "pure" HSP families may have abnormal nerve conduction velocities. ${ }^{12}$ In the AMN subtype of ALD, while abnormalities of peripheral nerve function are frequent, they are not a universal finding. ${ }^{13}$

In the present case, the correct diagnosis of X-linked ALD was made because the appropriate diagnostic test was done, but it is clear that X-linked ALD continues to be underdiagnosed. ${ }^{3}$ This is particularly relevant as the severe childhood form of the condition can result from the same mutation that underlies AMN, and the consequences for genetic counselling of incorrect diagnosis are therefore very significant, even tragic. Therefore, X-linked ALD should be considered in the differential diagnosis of any HSP, where male to male transmission is absent, and in apparently sporadic cases of spastic paraparesis.

\section{Authors' affiliations}

C J Shaw-Smith, E Reid, Department of Medical Genetics, University of Cambridge, UK

S J G Lewis, Department of Neurology, Addenbrooke's Hospital, Cambridge, UK

Competing interests: none declared

Correspondence to: Dr E Reid, Department of Medical Genetics, Box 134, Addenbrooke's Hospital, Cambridge, CB2 2QQ, UK; ereid@hgmp.mrc.ac.uk

Received 10 July 2003

In revised form 29 September 2003

Accepted 30 September 2003

\section{REFERENCES}

1 Reid E. Science in motion: common molecular pathological themes emerge in the hereditary spastic paraplegias. J Med Genet 2003;40:81-6.

2 Fink JK. Hereditary spastic paraplegia. In: Rimoin DL, Pyeritz RE, Connor JM, Korf BR, eds. Emory and Rimoin's principles and practice of medical genetics. 4th ed. London: Harcourt UK, 2002:3124-5.

3 Watkins PA, Gould SJ, Smith MA, et al. Altered expression of ALDP in Xlinked adrenoleukodystrophy. Am J Hum Genet 1995;57:292-301.

4 Moser HW, Smith KD, Watkins PA, et al. X-linked adrenoleukodystrophy. In: Scriver CR, Beaudet AL, Valle D, Sly WS, eds. The metabolic and inherited basis of inherited disease. 8th ed. New York: McGraw Hill, 2001:3257-301.

5 Menage P, Carreau V, Tourbah A, et al. [Symptomatic heterozygotic adrenoleukodystrophy in adults. 10 cases.] Rev Neurol (Paris) 1993;149:445-54, Article in French.

6 Moser HW, Moser AB, Naidu S, et al. Clinical aspects of adrenoleukodystrophy and adrenomyeloneuropathy. Dev Neurosci 1991;13:254-61.

7 Maris T, Androulidakis EJ, Tzagournissakis M, et al. X-linked adrenoleukodystrophy presenting as neurologically pure familial spastic paraparesis. Neurology 1995:45:1101-14.

8 Hedera P, DiMauro S, Bonilla E, et al. Phenotypic analysis of autosomal dominant hereditary spastic paraplegia linked to chromosome 8q. Neurology 1999;53:44-50.

9 Kumar AJ, Kohler W, Kruse B, et al. MRI findings in adult-onset adrenoleukodystrophy. AJNR Am J Neuroradiol 1995; 16:1227-37. 
10 Moser HW, Moser AB, Steinburg SJ. X-linked adrenoleukodystrophy. GeneReviews 2002; www.genetests.org (accessed 26 August 2002). 11 Boehm CD, Cutting GR, Lachtermacher MB, et al. Accurate DNA-based diagnostic and carrier testing for X-linked adrenoleukodystrophy. Mol Genet Metab 1999;66:128-36.
12 Schulte T, Miterski B, Bornke C, et al. Neurophysiological findings in SPG4 patients differ from other types of spastic paraplegia. Neurology 2003;60:1529-32.

13 Chaudhry V, Moser HW, Cornblath DR. Nerve conduction studies in adrenomyeloneuropathy. J Neurol Neurosurg Psychiatry 1996;61:181-5.

\section{HISTORICAL NOTE}

\section{Friedreich's ataxia}

$\mathrm{F}$ riedreich's ataxia, a spinocerebellar degeneration, is an autosomal recessive disease of the cerebellum, spinal cord, and peripheral nerves. Symptoms generally begin before puberty and include an ataxic gait, dysarthria, loss of reflexes, and variably nystagmus, kyphoscoliosis, and pes cavus. Heart disease usually develops, death often resulting from heart failure or dysrhythmia. Diabetes occurs in about one third of patients. Most are wheelchair bound within 1520 years of the onset.

Nikolaus Friedreich described the disease in $1863 .{ }^{1} \mathrm{He}$ described six patients in two families. ${ }^{2}$ He added three other patients in the 1876/1877 papers. ${ }^{3}$ A typical patient, Charlotte L, aged 49 , had had symptoms from the age of 18 and was admitted to hospital in 1862. By 1876 she could not walk; she showed nystagmus, nodding tremor of the head, poor balance, and kyphoscoliosis. Her legs were paralysed, the feet in equinovarus; sensation in the legs was impaired.

Friedreich found:

"Speech is to a large extent distorted, more than at discharge from the clinic thirteen years ago. The patient articulates so badly, that one often hardly understands the words... And the pupils [show] no abnormalities... The locomotor coordination of the upper limbs is impaired to the highest degree, much more than at the first visit in the clinic...writing has become almost impossible; directing the spoon to the mouth...happens with many additional movements deviating from the correct line and from the target. Closing the eyes does not increase the ataxic symptoms... Stronger stimuli at the sole of the foot generate rather brisk [cutaneous] reflexes; yet the tendon reflexes of Erb are absent."

He differentiated the early age of onset, hereditary tendency, slow progression, and the absence of sensory loss in the early stages, from tabes dorsalis. ${ }^{4}$

The four patients' postmortems showed degeneration of the dorsal columns. Microscopy showed neurogenic atrophy and demyelination. Clarke's column and the hypoglossal nuclei were degenerate. Friedreich shrewdly observed fatty degeneration of the heart in three cases, which he associated with the tendency of the patients to collapse.

His belief that he had discovered a new disease was contentious. Several thought it was a variant of tabes or multiple sclerosis. ${ }^{12}$ But, Gowers acknowledged "familial locomotor ataxy or Friedreich's disease" in $1880^{5}$ and in his Manual (1886) commented on 65 cases in 19 families: "the family tendency of the disease...shown by the affection... of brothers and sisters", 6 and mentioned 57 cases reviewed by Everett Smith in $1885 .{ }^{7}$ One year later, Bury summarised 100 published instances. ${ }^{8}$

The approval of Friedreich's conclusions, however, had to await Charcot's demonstration ${ }^{9}$ of a young sufferer from a hereditary ataxia, which did not conform to diagnoses of tabes or multiple sclerosis.

Nikolaus Friedreich was born in Würzburg in 1825, son of Johannes Baptist Friedreich (1796-1862) and grandson of Nikolaus Anton Friedreich, both professors of medicine in Würzburg. Friedreich received his doctorate in that city in 1850, then became Privatdozent in pathology and therapy.

When the famous Virchow came to Würzburg, Friedreich became a devotee, and considered abandoning medicine for pathology. Virchow went to Berlin in 1857, thus Friedreich was appointed Professor of Pathological Anatomy at Würzburg, and, in 1858, to the Chair of Pathology and Therapy and Director of the medical clinic at Heidelberg, where he remained until he died.

Both physician and pathologist, Friedreich maintained a successful private practice. He believed "the principles of cellular pathology have become the cynosure in the labyrinth of pathological process". Enormous energy characterised his clinical and laboratory research; and many acclaimed his teaching ability. Kussmaul, Friedrich Schultze, and Erb were his acolytes. He published eight major treatises and 51 other works that included the first description of paramyoclonus multiplex (Friedreich's disease), progressive muscular atrophy, heart disease, and possibly the first description of acute leukaemia (1857).

He was loyal to his friends but a sensitive ${ }^{10}$ and suspicious man, who habitually appeared miserable and oppressed. He died from a ruptured aortic aneurysm.

Several genes code for autosomal dominant cerebellar ataxia (ADCA) and a few for autosomal recessive ataxias. The gene for Friedreich's ataxia was mapped to chromosome 9 in 1988. The frataxin gene codes for a 210 amino acid protein of unknown function; the mutation is an unstable expansion of a GAA repeat in the first intron inherited from both parents. ${ }^{11}$ Friedreich's ataxia results from lack of frataxin in cells of the brain, nerves, heart, and pancreas. The gene encoding this protein is susceptible to a particular kind of DNA mutation, a triplet repeat expansion. Most are homozygous for the GAA expansion. The clinical features relate to the number of GAA repeats; formes frustes carry less repeats than typical patients. ${ }^{12}$

J M S Pearce

304 Beverley Road, Analby, Hull HU10 7BG, UK; imspearce@freenet.co.uk doi: 10.1136/jnnp.2003.022681

\section{References}

1 Friedreich $\mathrm{N}$. Ueber degenerative atrophie der spinalen Hinterstränge Virchow's Arch path Anat 1863;26:391-419, 433-59, and 1863;27:1-26.

2 Keppel Hesselink JM. A discussion from the previous century: multiple sclerosis or tabes dorsalis; or Friedreich's disease? Ned Tijdschr Geneeskd 1986;130:2353-6.

3 Friedreich N. Ueber Ataxia mit besonderer Berücksichtigung der hereditären Formen. Virchow's Arch path Anat 1876;68:145-245 and 1877;70:140-52.

4 Tyrer JH. Friedreich's ataxia. In: Vinken PJ, Bruyn GW, DeJong JMBV, eds. Handbook of clinical neurology. Volume 21, System disorders and atrophies, part 1. Amsterdam: North-Holland Publishing Company, 1975:359-64.

5 Gowers WR. A family affected with locomotor ataxy. Clin Soc Trans 1880;14:27-36.

6 Gowers WR. A manual of diseases of the nervous system. Volume 1. London: Churchill, 1886:349-56.

7 Smith WE. Hereditary or degenerative ataxia. Six cases in one family. Death of one case, and autopsy. Boston Med Surg J 1885;113:361-8.

8 Bury JS. A contribution to the symptomatology of Friedreich's disease. Brain 1886;9:145-77.

9 Goetz CG. Charcot the clinician. The Tuesday lessons. New York: Raven Press, 1987:141-63.

10 Erb W. Heidelberger Professoren aus dem 19 Jahrhundert. Volume 2. Heidelberg: Winter, 1903 (Biographical account).

11 Campuzano V, Montermini L, Molto MD, et al. Friedreich's ataxia: autosomal recessive disease caused by an intronic GAA triplet repeat expansion. Science 1996;271:1423-7.

12 Brice A. Unstable mutations and neurodegenerative disorders. J Neurol 1998;245:505-10. 